malignant disease has been found in animals treated with cyclophosphamide.

In patients treated with cyclophosphamide symptoms referrable to the urinary tract may be severe and life-threatening. An acute transient cystitis which recovers when the drug is discontinued is the commonest feature and this is often associated with severe haematuria, dysuria, and increased frequency. Patients may, however, have no symptoms at all in spite of appreciable fibrosis and contraction of the bladder wall. Thus disease of the bladder is an important complication of cyclophosphamide therapy, and should when cyclosphosphamide is used in non-malignant conditions be taken into account as well as the recognized possibility of increasing the incidence of malignant disease. Since animal studies have suggested that the complication may be prevented by diuresis, it is a wise precaution to ensure that patients are adequately hydrated.

'Clayson, D. B., and E. H. Cooper, Advances in Cancer Research, 1970, 13,

280. 2 Pilips, F. S., Sternberg, S. S., Cronin, A. P., and Vidal, P. M., Cancer Research, 1961, 21, 1577 .

Koss, L. G., Laboratory Investigation, 1967, 16, 44.

- Chaves, E., Revue Francaise d'Etudes Cliniques et Biologiques, 1968, 13, 56 5 Forni, A. M., Koss, L. G., Geller, W., Cancer, (Philadelphia), 1966, 96, 313. - Rubin, J. S., and Rubin, R. T., Fournal of Urology, 1966, 96, 313.

Johnson, W. W., and Meadows, D. C., New England fournal of Medicine, $1971,284,290$.

\section{Ileus and Pseudo-obstruction}

The gut's propulsive activity nearly always ceases for a time after abdominal operations. This is probably more the result of reflux inhibition, mediated by the splanchnic nerves, than a true paralysis, for it can be prevented experimentally by cutting those nerves. ${ }^{1}$ Intestinal activity usually returns a few hours after the operation has been completed, but gastric motility takes considerably longer to return, thus accounting for the delay before feeding by mouth becomes possible. ${ }^{23}$

Occasionally, as J. Neely and B. N. Catchpole have recently emphasized, ${ }^{4}$ a more severe disturbance supervenes, with distension of the gut by gas or fluid and with complete constipation. The factors which mediate the change from the simple physiological inactivity after operation to the second condition of apparent paralysis are ill-understood. Distension of the gut by itself is sufficient to reduce blood flow to the intestinal wall, 5 and theoretically a self-perpetuating pattern of distension leading to reduced blood flow followed in turn by reduced motor activity in the ischaemic bowel leading to further distension is easy to recognize. Nervous inhibition may also be an important mediator of this condition.

The well-established forms of treatment include the regimen of intravenous drip and gastric suction, special care being taken to correct potassium depletion. The removal of swallowed air by gastric suction is important in preventing further gaseous distension. Since there is no physical obstruction, various pharmacological methods of stimulating propulsive activity have been tried, such as the administration of cathartics, but without success. A more fruitful approach has been to encourage parasympathetic motor activity by the administration of drugs which either prevent the destruction of acetylcholine by cholinesterase, such as neostigmine, or are cholinergic agents, such as bethanecol, which has the advantage that it lacks the nicotinic side effects of carbachol. Neely and Catchpole emphasize the meed to exclude obstruc- tion as a cause of the patient's symptoms and illustrate the value of the pharmacological approach by reference to three patients in whom peristaltic activity was promptly restored after intravenous infusions of guanethidine combined with bethanecol or neostigmine, or of phentolamine and neostigmine. Two of these patients had had abdominal operations, one for appendicitis and the other for obstruction due to an ileal band. The third, a woman of 72 , developed apparent obstruction six days after the insertion of a h:p joint prosthesis, but was shown radiographically to have gas in all parts of the gastrointestinal tract.

This syndrome of pseudo-obstruction, as particularly exemplified by the third patient, has been well described. 67 It tends to develop in elderly patients and is frequently associated with an acute infection such as pneumonia or with cardiac or renal failure. Clinically it needs to be distinguished not only from organic internal obstruction but, for instance, from the apparent acute obstruction which often develops in association with acute pancreatitis or cholecystitis. Other potential sources of confusion include ischaemic disease of the gut, porphyria, lead poisoning, and intestinal amyloidosis. ${ }^{8} \mathrm{~A}$ further curious variety of chronic pseudo-obstruction has also been reported in association with steatorrhoea. 9

It is therefore possible to recognize separate groups of chronic and acute pseudo-obstruction and to divide the latter into varieties associated with localized intra-abdominal disease and with more generalized disease. A particularly helpful diagnostic feature is the presence of gas throughout the small and large intestine. Detection of it should always cause hesitation before undertaking laparotomy on an apparently obstructed patient.

\footnotetext{
1 Bayliss, W. M., and Starling, E. H., fournal of Phvsiology, 1899, 24, 99 Wells, C., Rawlinson, K., Tinckler, L., Jones, H., and Saunders, J., Lancet, 1961, 2, 136.

3 Rothnie, N. G., Harper, R. A. K., and Catchpole, B. N., Lancet, 1963, 2 64.

Neely, J., and Catchpole, B. N., British fournal of Surgery, 1971, 58, 21.

Jacobson, E. D., Brobmann, G. F., and Brecher, G. A., Gastroenterology, $1970,58,575$

Stephens, F. O., British Medical fournal, 1962, 1, 1248.

Dudley, H. A. F., Sinclair, I. S. R., McLaren, I. F., McNair, T. J., and Newsam, I. E., Fournal of the Royal College of Surgeons of Edinburgh, 1958, 3, 206.

Legge, D. A., Wollaeger, E. E., and Carlson, H. C., Gut, 1970, 11, 764

Naish, J. M., Capper, W. M., and Brown, N. J., Gut, 1960, 1, 62.
}

\section{Radiation Hazards}

How much is enough? For drugs the answer is usually known. For environmental pollutants the decision is usually influenced by speculation and emotion. Radiation hazards fall between these extremes, with a modest amount of scientific understanding and undertones of anxiety or alarm. The early radiologists underestimated the dangers, but their experience provided a basis for the strict regulations which now limit occupational exposure. More recently there has been concern over the effects of radiation on the population at large, especially from radioactive fallout and diagnostic radiology.

Though radiation has been studied more extensively than any other environmental hazard, the definition of safe levels of exposure for the general public is still a question for informed judgement rather than exact calculation. A new American report ${ }^{1}$ gives a useful summary of present knowledge (and ignorance) on this matter. Noting that the average 